\title{
Animal Morality: What It Means and Why It Matters
}

\author{
Susana Monsó ${ }^{1}$ (i) · Judith Benz-Schwarzburg ${ }^{1} \cdot$ Annika Bremhorst $^{2,3}$
}

Received: 10 April 2018 / Accepted: 24 September 2018 / Published online: 27 September 2018

(c) The Author(s) 2018

\begin{abstract}
It has been argued that some animals are moral subjects, that is, beings who are capable of behaving on the basis of moral motivations (Rowlands 2011, 2012, 2017). In this paper, we do not challenge this claim. Instead, we presuppose its plausibility in order to explore what ethical consequences follow from it. Using the capabilities approach (Nussbaum 2004, 2007), we argue that beings who are moral subjects are entitled to enjoy positive opportunities for the flourishing of their moral capabilities, and that the thwarting of these capabilities entails a harm that cannot be fully explained in terms of hedonistic welfare. We explore the implications of this idea for the assessment of current practices involving animals.
\end{abstract}

Keywords Nonhuman animals · Animal ethics · Animal morality $\cdot$ Moral emotions · Capabilities approach $\cdot$ Welfarism $\cdot$ Harm

\section{Introduction}

Rowlands (2011, 2012, 2017) has recently argued that some nonhuman animals (hereafter 'animals') may be moral creatures, understood as creatures who can behave on the basis of moral motivations. He has argued that, while animals probably lack the sorts of concepts and metacognitive capacities necessary to be held morally responsible for their behaviour, this only excludes them from the possibility of counting as moral agents. There are, however, certain moral motivations that, in his view, may be reasonably thought to fall within the reach of (at least some) animal species, namely, moral emotions such as "sympathy and compassion, kindness, tolerance, and patience, and also their negative counterparts such as anger, indignation,

Susana Monsó

susanamonso@gmail.com

1 Messerli Research Institute, University of Veterinary Medicine Vienna, Veterinärplatz 1, 1210 Vienna, Austria

2 Division of Animal Welfare, VPHI, University of Bern, 3012 Bern, Switzerland

3 Animal Behaviour, Cognition and Welfare Research Group, School of Life Sciences, University of Lincoln, Lincoln LN6 7TS, UK 
malice, and spite", as well as "a sense of what is fair and what is not" (Rowlands 2012, 32). If animals do indeed behave on the basis of moral emotions, they should, he argues, be considered moral subjects, even if their lack of sophisticated cognitive capacities prevents us from holding them morally responsible. ${ }^{1}$

The empirical evidence gathered until now suggests that Rowlands may be on the right track and that some animals are indeed capable of behaving morally. Some studies, for instance, have found that animals are sometimes willing to help others when there is no direct gain involved, or even a direct loss. Such apparently altruistic behaviour has been shown by rats (Church 1959; Rice and Gainer 1962; Evans and Braud 1969; Greene 1969; Bartal et al. 2011; Sato et al. 2015), pigeons (Watanabe and Ono 1986), and several primate species (Masserman et al. 1964; Wechkin et al. 1964; Warneken and Tomasello 2006; Burkart et al. 2007; Warneken et al. 2007; Lakshminarayanan and Santos 2008; Cronin et al. 2010; Horner et al. 2011; Schmelz et al. 2017). It has further been found that some animals will offer apparent consolation to individuals in distress, a behaviour that is thought to be triggered by empathic processes and has been observed in primates (de Waal and van Roosmalen 1979; Kutsukake and Castles 2004; Cordoni et al. 2006; Fraser et al. 2008; Clay and de Waal 2013; Palagi et al. 2014), corvids (Seed et al. 2007; Fraser and Bugnyar 2010), canines (Cools et al. 2008; Palagi and Cordoni 2009; Custance and Mayer 2012), elephants (Plotnik and de Waal 2014), horses (Cozzi et al. 2010), budgerigars (Ikkatai et al. 2016), and prairie voles (Burkett et al. 2016). A few studies have also found an aversion to inequity in chimpanzees (Brosnan et al. 2005, 2010), monkeys (Brosnan and de Waal 2003; Cronin and Snowdon 2008; Massen et al. 2012), dogs (Range et al. 2008), and rats (Oberliessen et al. 2016), which suggests the presence of a sense of fairness in these species. ${ }^{2}$

While we believe that all this evidence provides prima facie support for Rowlands' position, in this paper our aim is not to engage in an empirical or conceptual assessment of the claim that animals can be moral subjects. Rather, we shall grant that moral subjecthood in animals is at least a theoretical possibility with some

\footnotetext{
1 The idea that some animals have some degree of moral agency has also been defended by other authors, such as Sapontzis (1987), Pluhar (1995), De Grazia (1996), Shapiro (2006) and Andrews and Gruen (2014). We focus on Rowlands' approach for present purposes because it is the most detailed philosophical account of animal morality to date, and also because we find the distinction between moral subjects and moral agents to be very useful when discussing animal morality.

2 In addition to these systematic studies, which document animals engaging in apparently moral behaviour towards both humans and conspecifics, one can easily come across many relevant anecdotes. For instance, there are reports of dolphins helping other dolphins (Park et al. 2012), and even humans (Bekoff and Pierce 2009, 108).
} 
empirical plausibility. ${ }^{3}$ Our focus, instead, is going to be on determining the ethical consequences that follow from considering that a certain animal is a moral subject.

Morality has long been understood as a feature that distinguishes humanity from the rest of the animal kingdom. It is not uncommon to find authors who use this distinguishing characteristic as a basis for denying moral rights to animals. McCloskey, for instance, argues that "[w]ithout a moral capacity, actually or potentially, there can be [...] no moral exercise or waiving of a moral right, and hence no moral rights possessed by mammals that lack moral autonomy, actually and potentially" (McCloskey 1987,79$)$. The idea that only moral beings are entitled to moral consideration is especially salient in the contract tradition in ethics, as exemplified by the theories of Hobbes, Locke, and Kant, and can be traced back to Epicurus, who claimed: “[w] ith regard to those animals that do not have the power of making a covenant to not harm one another or be harmed, there is neither justice nor injustice" (KD, §32). This idea is also found in contemporary contractualism. For instance, Rawls states that "equal justice is owed to those who have the capacity to take part in and to act in accordance with the public understanding of the initial situation" in which the principles of justice are chosen (Rawls 1971, 505). This means that, in his view, "it is precisely the moral persons who are entitled to equal justice," where moral persons are understood as those beings who are "capable of having [...] a conception of their good," as well as "a sense of justice" (Ibid.).

While any theory that requires individuals to be moral in order to matter morally can be questioned (see, for instance, Rowlands 2002 for a critique of the Rawlsian position), the fact remains that characterising humans as the only moral creatures may contribute to justifying a view of our species as superior to the rest, and of nature as being somehow at our disposal. ${ }^{4}$ This is exemplified by Machan, who states that "[n]ormal human life involves moral tasks, and that is why we are more important than other beings in nature," a claim he uses to justify making "the best use of nature for our success in living our lives" (Machan 2002, 10-11). Any research project that explores the continuity between our species and the rest of the animal kingdom has the potential to deliver results that can serve to subvert this view of humanity, and consequently question our widespread exploitation of animals (Benz-Schwarzburg and Knight 2011; Benz-Schwarzburg 2012). Determining that

\footnotetext{
3 While the possibility of animal morality is gaining increasing support from scholars, there are authors who have expressed dissenting views, on both empirical and conceptual grounds. There are, for instance, empirical critiques of the 'fairness' experiments by Brosnan and De Waal (e.g. Penn et al. 2008), as well as the 'empathy' studies on rodents (e.g. Schwartz et al. 2017). There are also conceptual critiques that focus on whether these studies provide evidence of specifically moral motivations (see e.g. Korsgaard 2006; Carron 2018 for critiques of De Waal's interpretation of the relevant studies). For a comprehensive overview of the conceptual disagreements in the animal morality debate, see Fitzpatrick (2017). For an up-to-date discussion of the empirical evidence and the debates on how to interpret it, see Andrews and Monsó (in preparation).

4 This line of thinking is deeply rooted in different cultures. In the Judeo-Christian tradition, for example, human superiority has traditionally been interpreted as granting a right to dominate and exploit nature. Some modern theologians, however, argue that human superiority should instead be interpreted as implying a duty of stewardship (e.g. Linzey and Cohn-Sherbok 1997).
} 
morality extends beyond the human species would thus help undermine any claims of human superiority that could be used to justify the mistreatment of animals. ${ }^{5}$

However, we will argue that this is not the only ethical consequence attached to the idea of animals as moral subjects. It is generally assumed that the kind of ethical treatment a certain being is entitled to depends upon the type of being she is. While this idea has been questioned by some authors (e.g. Crary 2010), most ethicists consider that a species' features are the cornerstone of the type of ethical treatment its members deserve. White, for example, links the very idea of ethics to the appreciation of a species' capacities. He does so by referring to the notion of vulnerability:

Ethics-our labeling actions as 'right' or 'wrong' - is grounded in the idea that the type of consciousness that we have gives us special capacities and vulnerabilities. When we label something as 'wrong', then, we're saying that it crosses the line with regard to not respecting some fundamental feature that makes us human. (White 2007, 155)

It seems, indeed, plausible to consider that the ways in which members of a species can be harmed make them vulnerable in certain specific ways, and, in turn, shape the kinds of duties we might hold towards them. For instance, it makes no sense to say of a non-sentient being that she has a right not to be subjected to unnecessary pain. Taking this idea as our point of departure, we will argue that there is a specific kind of harm that can affect moral subjects as such, and that certain specific rights or entitlements follow from this. And, importantly, we will argue that this specific kind of harm cannot be captured merely by saying that the individual is suffering, that her experiential welfare is impaired.

In order to defend this position, we are first going to introduce what we shall term the 'welfarist' position in animal ethics, which we will understand in a specific, and somewhat narrow, sense, and will constitute the focus of our critique. In the next section, we will construct a hypothetical example of an animal who has the ability to behave on the basis of a certain moral motivation and, thus, qualifies as a moral subject. Using Nussbaum's capabilities approach as our theoretical framework, we will then illustrate the kind of harm that can affect this individual because she possesses this motivation, and the entitlements that she has as a result of this. We will subsequently return to the welfarist position and argue that a purely welfare-oriented analysis of this individual's case would not capture the full dimension of this harm. In the final section before concluding, we will go back into the 'real world' and examine some of the practices involving animals using these considerations as our guide. Our aim will be to show how humans may be interfering with the moral subjecthood of animals in a way that constitutes a violation of their entitlements.

\footnotetext{
5 One could object here by saying that full moral status depends on full-fledged moral agency, which can be plausibly regarded as an exclusively human domain (barring any extraterrestrial moral agents). However, we assume that anyone who defends this position would be unable to satisfactorily address the so-called 'marginal cases' objection, namely, that some humans don't possess full-fledged moral agency, due to age or impairment, and yet we still want to grant them full moral status.
} 


\section{Welfarism and Animal Ethics}

We are going to argue that the ethical implications that follow from moral subjecthood cannot be captured solely in terms of welfare. The word 'welfare' has many different meanings, stemming from debates in axiology, political philosophy, animal ethics, and animal welfare science. For present purposes, we will use it in a narrow sense, to signify 'experiential welfare' or 'subjective quality of life,' in the hedonistic sense of these terms. Accordingly, the position that we shall call 'welfarism' boils down to the idea that hedonistic welfare, or hedonistic quality of life, is the only variable that matters when it comes to measuring well-being. ${ }^{6}$ This means that increases in wellbeing are understood to correlate with an improvement in the hedonistic aspects of an individual's life, and conversely, decreases in well-being are understood to correlate with a deterioration in these aspects. Thus, one cannot be made worse off (e.g. by having one's freedom or autonomy taken away) unless one feels worse off (either immediately or as a later consequence).

Welfarism is not necessarily tied to a particular normative theory. It is a theory about what is prudentially valuable, what constitutes well-being, but it does not tell us anything about how this value ought to be pursued. Thus, there can, in principle, be both consequentialist and deontological approaches to welfarism. What characterises the form of welfarism that we are concerned with, and constitutes the focus of our critique, is the endorsement of a hedonistic account of the good, according to which the only intrinsic good is pleasure (understood, in a broad sense, to encompass both physical pleasure and psychological enjoyment), and the only intrinsic bad is pain (understood, in a broad sense, to encompass both physical pain and psychological suffering).

There are several well-known problems that follow from hedonistic accounts of the good. These problems stem from two questionable claims involved in hedonism. On the one hand, one can question that all forms of pleasure are intrinsically good, for it seems that how one obtains pleasure also adds to its value or disvalue. On the other hand, there appear to be many other things that we value as intrinsically good besides pleasure. This is exemplified by the classic "experience machine" thought experiment (Nozick 1974, 42-45). This machine would provide us with a non-stop flow of pleasurable experiences if we were to be plugged into it instead of living our 'real' lives. The fact that we would not be willing to plug ourselves into it illustrates that there are other things we value in life besides pleasurable experiences. Among the things that are also proposed as intrinsically valuable, we can find freedom, knowledge, achievement, as well as relationships of friendship, care, and love (see, e.g., Rice 2013).

Some authors have developed more sophisticated forms of welfarism that are not defeated by Nozick's experience machine. For instance, Sumner has defended

\footnotetext{
${ }^{6}$ We use the term 'well-being' to refer, broadly, to how well life is going for an individual. We thus take welfarism to be a monistic theory that equates well-being with positive hedonistic welfare, and we understand pluralistic theories as defending the existence of other prudential goods that contribute to well-being.
} 
a form of welfarism that "requires that a subject's endorsement of the conditions of her life, or her experiences of them as satisfying or fulfilling, be authentic" (Sumner 1996, 139), which means that the subject has to be autonomous and properly informed. This authenticity condition allows Sumner to escape Nozick's objection. However, Sumner appears to not merely consider pleasure as intrinsically valuable, but also autonomy, since for him it is of high importance to preserve "the authority of welfare subjects to determine for themselves which goods they will pursue in their lives" (Ibid., 98). The value of autonomy appears to be intrinsic and not merely instrumental, for he does not simply present it as a tool to ensure enjoyable experiences, but appears to value it in itself (see, e.g. Ibid., $166 \mathrm{ff}$.). If this interpretation of Sumner is correct, then his theory does not qualify as 'welfarist' in the sense in which we are using the term.

Regardless of how Sumner's welfarism is best to be interpreted, our aim here is to criticise a less sophisticated form of welfarism, in which the sole criterion for determining the well-being of an individual is the presence or otherwise of pleasure and pain, broadly construed. Welfarism, thus understood, is not very popular as an account of human well-being, but it is a predominant approach when evaluating animal husbandry procedures and other forms of human-animal interaction. Welfarists consider that animals are harmed by humans only in those cases in which our treatment of them generates pain or suffering, or removes opportunities for pleasant or satisfying experiences. And conversely, an improvement in the way animals are treated is thought to exist whenever there is a decrease in suffering or an increase in joyful experiences. This is especially salient in scholars that attach to the so-called 'feelings school' within animal welfare science, for whom "welfare is all to do with what the animal feels, with the absence of negative subjective emotional states [...] and [...] the presence of positive subjective emotional states" (Duncan 2004, 88). ${ }^{7}$ Some animal ethicists also exemplify this position, like Rollin, who has argued that "how the animal feels subjectively, what it experiences, is the key feature of welfare or well-being" (Rollin 2004, 16). A further prominent example is Ryder's painism, which is founded on the idea that the property "that all bad things share [...] is that they all cause pain (in its broad sense)" (Ryder 1999, 36), and so the aim of animal ethics "should be to reduce the pain felt by individuals" (Ryder 1999, 40).

We believe that there is some truth to welfarism. There are certain moral problems with regards to which a welfarist approach provides us with a satisfactory analysis, for it is undoubtedly the case that pleasure and pain are, respectively, goodand bad-making properties of situations, other things being equal. Moreover, there is an undeniable advantage to welfarism. For those concerned with how animals are

\footnotetext{
7 Following Schmidt (2011, 158), welfare scientists can be broadly categorised into those that focus on the subjective aspects of animal well-being (e.g. Duncan 1993) and those that focus on objective aspects, such as biological functioning, the ability to cope with the environment (e.g. Broom 1991), or quantifiable measures of animal welfare such as behavioural indicators (e.g. Dawkins 2006). However, there are also welfare scientists that stress both (e.g. Webster 2005). Our critique of welfarism in this paper is directed at those scholars that focus on the subjective aspects. It is important to note, though, that in animal welfare science subjective quality of life is often considered a very dominant component of animal well-being.
} 
treated, welfarism is a good position to adopt, strategically, insofar as most people will agree that subjective quality of life matters to those animals who are sentient, while the existence of other prudential values that apply to animals' lives is a matter of some controversy. We acknowledge this advantage, but do not consider this to be sufficient reason, on its own, to fully embrace this approach. We consider that welfarism is problematic if we pretend it to account for all the components of a good life, and, conversely, it is also problematic if we pretend it to account for all the possible harms that can affect an individual. In the specific case of the moral subjecthood of animals, the ethical implications that follow from it, we shall argue, cannot be fully captured from a welfarist standpoint.

\section{A Thought Experiment: The Case of Sustitia}

We are going to defend the claim that if one is a moral subject, then one can be subjected to a specific type of harm that (1) cannot obtain when one lacks moral subjecthood, and (2) cannot be fully explained in terms of welfare. In order to defend this idea, we will use the example of a sow that we shall call Sustitia. To facilitate our critique of welfarism, we are going to build this example in two steps. First, we will offer a characterisation of Sustitia as an individual who is being harmed in a way that can be fully captured from a welfarist perspective. We shall call her Sustitia ${ }_{1}$. Then, we will turn Sustitia into a moral subject, for the purpose of illustrating how welfarism cannot give a proper account of the ethical implications in this case. We shall call this second individual Sustitia ${ }_{2}$. Both Sustitia $_{1}$ and Sustitia ${ }_{2}$ may resemble actual sows in certain respects, but it is very important to bear in mind that they are not meant to be real, or even realistic, sows, but rather two hypothetical constructs that we will use to illustrate our point.

\section{Sustitia ${ }_{1}$ : A Sentient Being}

Let us begin, then, with Sustitia ${ }_{1}$. We shall start from the assumption that Sustitia is a rather simple being, whose abilities are largely limited to the basic needs of nutrition, rest, and reproduction. What is noteworthy about Sustitia ${ }_{1}$ is her possession of sentience. This means, first of all, that she has an ability to experience physical sensations. She can experience pleasure, and she can also experience pain, where these have a subjective 'felt' quality to them. Pleasure feels good to Sustitia ${ }_{1}$, and pain feels bad. Sustitia ${ }_{1}$ can further experience affective states, and these too have a concrete phenomenal character. Some of these affective states are moods with no intentional object. Her happy moods and her sad moods also feel good and bad, respectively, to Sustitia ${ }_{1}$. Other affective states are emotions with intentional objects. There are things in her environment that she enjoys or feels happy about, and there are other things that she dislikes, that make her feel distressed, or sad, or angry, or fearful. Sustitia ${ }_{1}$ experiences different things in her environment as good or bad, depending on how they make her feel. 
Sustitia ${ }_{1}$ lives on a farm. Since the moment she reached adulthood, she has been kept in a stall that is too small for her to move around freely. All she can do is stand up and lie down, which causes her stress and pain. To facilitate cleaning, the floor of her stall is slatted, which causes her claws to overgrow, resulting in painful leg and claw injuries, shoulder lesions, and teat damage. The food she is fed is low in fibre, leading to painful stomach ulcers. She is forced to urinate and defecate in the same place where she sleeps, which she finds extremely unpleasant. A couple of times per year, she is made pregnant through artificial insemination. Her human handlers are not always properly trained, and the insemination is often painful and scary. When she is about to give birth, she is put into a farrowing crate, where she will be kept for four weeks in a row, and which restricts her movements even further, causing even more distress and pain. Once the piglets are weaned, she is put back in her stall, and the cycle begins again. ${ }^{8}$

As we can see, Sustitia ${ }_{1}$ is often in pain or distressed, and this psychological and physical suffering is a direct result of the way in which her human owners keep her. Theories in applied animal ethics tend to include a prohibition against causing unnecessary pain and suffering to animals. For instance, David DeGrazia's principle of nonmaleficence states that "[i]t is wrong to cause extensive unnecessary harm to others without their consent" (DeGrazia 2005; see also DeGrazia 1996, chapter 9). Given that-we are supposing-Sustitia ${ }_{1}$ 's suffering is un-consented and extensive, as well as questionable with regard to its necessity, ${ }^{9}$ the practices that give rise to it should consequently be brought into question.

As things stand in this example, it seems reasonable to say that Sustitia ${ }_{1}$ is being harmed by her owners, given that these husbandry conditions lead her to suffer almost continuously. The harm that Sustitia ${ }_{1}$ undergoes is by no means negligible. On the contrary, a plausible case could be made to argue that a fundamental right of Sustitia $_{1}$ - the right not to be subjected to extensive and unnecessary suffering - is being violated. We do not want to lessen the importance of this harm. However, we do want to highlight that this is a harm that can be fully accounted for in terms that refer solely to Sustitia ${ }_{1}$ 's subjective experience. Of course, one could argue that, on account of being a farm animal, Sustitia ${ }_{1}$ is also being harmed because she has had

\footnotetext{
${ }^{8}$ Even though Sustitia ${ }_{1}$ is a hypothetical example, her life conditions do not differ much from those of sows in industrial farms. See EFSA (2007) for a comprehensive review of the welfare problems involved in pig husbandry.

9 What constitutes unnecessary suffering is, for sure, debatable. Farm animals are routinely subjected to a series of painful or stressful procedures that are deemed necessary out of economic interests. Farrowing crates, for instance, are used to prevent the sows from rolling over and crushing the piglets. However, studies have shown that sows kept in an enriched environment, with more space and access to straw and sand, are less likely to crush their piglets and more likely to respond to a piglet's distress cries by standing up (Herskin et al. 1998). Providing such environmental enrichment, together with the extra space required, would entail extra costs for the farmers, thus ultimately raising the price of pork. Are farrowing crates then "necessary"? It depends on the normative ethics one subscribes to. From the perspective of some utilitarian welfare ethics, it might be permissible to weigh the sows' interest in not suffering against the farmers' interest in earning a living. In contrast, from the perspective of other ethical accounts (including other consequentialist approaches, and for sure an animal rights approach), this might not be permissible, as the interest in not suffering ranks in principle higher than economic interests (at least as long as the latter do not constitute a matter of life or death for the farmer or consumer).
} 
her freedom taken away from her, or because she is being commodified or exploited. These are fair points, but we want to bracket the harm that comes from her overall life experience and focus on the specific harm that results directly from her husbandry conditions: the inadequate flooring, the restricted space, and so on. The latter is a harm that takes the form of a subjective negative experience. Because these conditions make her suffer, and her suffering is a bad thing, Sustitia ${ }_{1}$ is harmed by them. If Sustitia ${ }_{1}$ were to find these living conditions pleasant or enjoyable, then they wouldn't harm her (although, of course, it might still be wrong to exploit her). The harm that Sustitia ${ }_{1}$ undergoes as a direct result of her husbandry conditions consists of her suffering. It is a welfare problem.

\section{Sustitia ${ }_{2}$ : A Moral Subject}

Our characterisation of Sustitia $_{1}$ has not provided us with any reason to think that she is a moral subject, for she has been described as a fairly simple individual with entirely self-centred interests. Now, let's turn Sustitia into a moral subject. Accordingly, we shall now refer to her as Sustitia 2 . What makes her different from Sustitia is that Sustitia $_{2}$ does not just suffer due to her own life conditions, she is also concerned with the well-being of the sows and piglets in her environment. She is surrounded by sows who are kept in the same conditions as her, and who are thus displaying continuous signs of distress. She also has to witness piglets undergoing tail-docking, teeth-clipping, and castration without anaesthesia or analgesia, ${ }^{10}$ and she is not indifferent to their pain and distress.

Sustitia $_{2}$ is characterised by the possession of a mechanism in her brain that ensures that whenever she witnesses a conspecific in distress, she too undergoes a form of distress ${ }^{11}$ that (1) is intentionally directed at the distress of the conspecific, and (2) has an urge to engage in affiliative behaviour built into it. This means that, when Sustitia $_{2}$ witnesses the distress of any of the conspecifics in her environment, she automatically feels distressed about their distress, and this reliably compels her to comfort them. We are going to refer to this capacity of Sustitia ${ }_{2}$ as her

\footnotetext{
${ }^{10}$ In this respect, these hypothetical piglets are not so different from real piglets, as these are all routine procedures in livestock management (RSPCA 2016).

${ }^{11}$ Sustitia $_{2}$ may share this capacity with actual pigs. Recent studies suggest that pigs possess a capacity for emotional contagion, for they tend to display behaviours associated with negative emotions (e.g. escape attempts, defecation) or positive ones (e.g. play behaviour, barks) depending on whether they are paired with a conspecific who has undergone a negative or a positive treatment, respectively (Reimert et al. 2013; Reimert et al. 2015; Goumon and Špinka 2016). In fact, she also appears to share this capacity with chimpanzees (Parr 2001), geese (Wascher et al. 2008), dogs (Yong and Ruffman 2014; Huber et al. 2017), mice (Langford et al. 2006; Jeon et al. 2010), rats (Knapska et al. 2006; Atsak et al. 2011), prairie voles (Burkett et al. 2016), and chickens (Edgar et al. 2011). Studies on emotional contagion often involve animals undergoing negative stimuli in order to determine whether the witnessing animals get stressed, too. While this is an issue that goes beyond the scope of this paper, we would like to note that these sorts of experiments may be ethically problematic and should not remain unquestioned.
} 
'sympathy' 12 and we shall suppose, for the sake of upcoming arguments, that this is a common characteristic to her species, even though the jury is still out on this.

We can plausibly classify Sustitia 2 's sympathy as a moral emotion, given that it is an emotion that has the other's welfare as its focus (i.e., the other's welfare is its intentional object), and motivates a response that is meant to act upon the other's situation (i.e., Sustitia ${ }_{2}$ wants to improve her conspecifics' situation, and not just her own, as was the case with Sustitia ${ }_{1}$ ). And, indeed, on account of her possession of sympathy, Sustitia 2 now fulfils the minimal conditions put forward by Rowlands to count as a moral subject:

$\mathrm{X}$ is a moral subject if $\mathrm{X}$ possesses (1) a sensitivity to the good- or bad-making features of situations, where (2) this sensitivity can be normatively assessed, and (3) is grounded in the operations of a reliable mechanism (a "moral module"). (Rowlands 2012, 230)

The possession of sympathy entails a sensitivity to the morally relevant property of distress. The kind of sensitivity that Sustitia 2 has to distress corresponds to the one Rowlands requires of moral subjects, for he establishes that "[m]oral subjects are ones who are sensitive to the good- and bad-making features of situations in the sense that they entertain intentional content emotionally" (Ibid., 230, emphasis by authors). Sustitia 2 's sensitivity, in turn, can be normatively evaluated, both internally and externally. From an internal perspective, we can say that, when Sustitia 2 comforts her conspecifics, she is doing so for morally right reasons, since her sympathy implies experiencing as bad something that is, in fact, bad (i.e., the conspecific's distress). At the same time, from an external perspective, Sustitia 2 's sympathy is morally good because it will tend towards alleviating her conspecifics' distress, thus diminishing the amount of bad in the world. Moreover, her emotional reaction to others' distress is not merely accidental or contingent. Instead, it is a systematic reaction grounded in the operations of a reliable internal mechanism-one which, we are supposing, is shared by all members of her species. Due to all this, Sustitia 2 qualifies as a moral subject, in Rowlands' sense. ${ }^{13}$

Now, let's imagine that one day, Sustitia 2 witnesses a particular piglet having his tail docked. The piglet squeals in pain, and Sustitia,'s sympathy kicks in. She feels distressed at the piglet's distress, and with this feeling comes a sudden urge to engage in affiliative behaviour, in order to calm the piglet down. ${ }^{14}$ However, the

\footnotetext{
12 When referring to Sustitia 2 's mechanism as her 'sympathy,' we are following a trend within the animal morality debate that considers sympathy to be a form of empathy that entails the (partial) adoption of another's emotional state, together with a possession of a clear self-other distinction, an understanding that the other is in need or suffering, and an intention to ameliorate the other's situation (see, e.g., de Waal 2008, 283). There is, however, a big definitional debate surrounding both sympathy and empathy, which we do not intend to take a stand on. Referring to Sustitia 2 's mechanism as 'sympathy' is meant for ease of exposition, but we do not necessarily subscribe to any particular definition of this term.

13 For a detailed explanation of the importance of these traits from a moral perspective, see Rowlands (2012); also Monsó (2017).

14 Indeed, this is the usual effect when animals engage in affiliative behaviour directed at a distressed conspecific (see, e.g., Kikusui et al. 2001; Fraser et al. 2008; Clay and de Waal 2013; Smith and Wang 2014; Burkett et al. 2016).
} 
stall that Sustitia 2 's caretakers have placed her in acts as a physical barrier and separates her from the piglet, thus preventing her from comforting him. This situation is repeated over and over again. Whenever Sustitia 2 sees, hears, or smells any of her conspecifics in distress, she wants to comfort them, but is prevented from doing so on account of the existence of this barrier. Given that, under normal circumstances, her sympathy would result in affiliative behaviour, we can say that the barrier prevents this moral motivation from operating fully or correctly.

As in the case of Sustitia ${ }_{1}$, it is undoubtedly true that Sustitia ${ }_{2}$ 's welfare is being compromised here. Her sympathy encompasses feelings of distress, so she will suffer whenever she perceives a conspecific in distress. As before, we do not intend to lessen the importance of Sustitia,'s psychological suffering. However, we believe that there is something more going on in this example, something that can't be specified in terms of welfare alone. We are going to argue that, in such a situation, Sustitia ${ }_{2}$ would be the subject of a type of harm that would not be captured by merely saying that she is suffering; that her experiential welfare is being compromised. This something more that is going on stems from the fact that Sustitia ${ }_{2}$ is being prevented from exercising her moral subjecthood. In the following section, we present a way of capturing the harm that this implies.

\section{Moral Emotions and the Capabilities Approach}

We are going to defend the idea that any theory that focuses solely on welfare won't be able to account for all of the problems present in the example of Sustitia ${ }_{2}$, and other similar ones. The defence of this idea, which will take place in Theoretical Implications: Moving Beyond Welfarism section, will rely on the use of an alternative normative framework that can capture the harm we are speaking of. Rather than attempting to build from scratch a theory that can capture our intuitions, we shall make use of a well-known theory that has already proved quite solid: the capabilities approach, which was introduced into animal ethics by Nussbaum $(2004,2007)$. We have chosen this theory due to (1) its individualistic character, (2) the importance it gives to social abilities, and (3) its reliance on a pluralistic theory of well-being, all of which makes it a perfect candidate to use in support of our argument.

Since a defence of this theory is beyond the scope of this paper, we will proceed by assuming its correctness. Those readers who are not entirely convinced by Nussbaum's approach should, however, bear in mind that the use of this theory is for argumentative purposes and that alternative frameworks could also be employed here. For example, Purves and Delon (2018) have recently given an account of how animals' lives can be meaningful that could be used to argue that a life in which an animal is allowed to exercise her moral subjecthood is more meaningful to her, and thus better. ${ }^{15}$ The integrity approach defended by Rutgers and Heeger (1999) could also be extended to argue that a life in which an animal cannot exercise her moral abilities violates the animal's psychological completeness, and thus harms her. With

15 In fact, the authors themselves hint at this idea (Purves and Delon 2018, 329). 
this in mind, let us now introduce the capabilities approach, and show how it can be used to conceptualise the harm that affects Sustitia $_{2}$ when she is prevented from exercising her sympathy.

\section{The Capabilities Approach}

When Nussbaum introduced the capabilities approach to animal ethics, she placed much emphasis on the idea that this approach doesn't focus merely on considerations related to pleasure and pain. Of course, this doesn't mean that there isn't importance attached to the idea of sentience. In fact, Nussbaum considers that the possession of sentience can be plausibly considered "a threshold condition for membership in the community of beings who have entitlements based on justice" (Nussbaum 2007, 361-362). But the capabilities approach moves beyond theories that focus solely on sentience, such as classical utilitarianism, by locating ethical significance in the existence of complex forms of life, and thus aiming to "see each thing flourish as the sort of thing it is" (Nussbaum 2004, 306).

Nussbaum considers that, for each species, there exists a series of capabilities, made up of those things that members of that species are "able to do and to be" (Nussbaum 2007, 71). Needless to say, if we are thinking of highly complex species, such as our own, the list of capabilities is immense. But out of all these capabilities, Nussbaum considers that each species has a set of "basic" capabilities, which are distinguished from the rest in that they can be "evaluated as both good and central" (Nussbaum 2004, 309), where "good" is understood as being intrinsically valuable, and "central" as being essential to the flourishing of members of that species as the sort of thing they are. In the case of human beings, the basic capabilities include some that can be shared with many other species, like "[b]eing able to move freely from place to place," and "[b]eing able to have good health," but also further capabilities that are species-specific, like "[b]eing able to use one's mind in ways protected by guarantees of freedom of expression," and "[b]eing able to form a conception of the good and to engage in critical reflection about the planning of one's life" (Nussbaum 2007, 76-77). The key idea, for our purposes, is the following:

Because the capabilities approach finds ethical significance in the flourishing of basic (innate) capabilities - those that are evaluated as both good and central $[. .$.$] - it will also find harm in the thwarting or blighting of those capabili-$ ties. More complex forms of life have more and more complex capabilities to be blighted, so they can suffer more and different types of harm. Level of life is relevant not because it gives different species differential worth per se, but because the type and degree of harm a creature can suffer varies with its form of life. (Nussbaum 2004, 309)

According to the capabilities approach, then, one is harmed when the agency of another results in a thwarting or blighting of one's basic capabilities. When a being is very complex, this doesn't necessarily mean that she will have the capacity to suffer more, but it does mean that she will be capable of suffering more types of harm than less complex beings, given that a higher complexity means a possession 
of more basic capabilities that can be thwarted. And, as we shall shortly discuss, the harm that comes from the thwarting of a being's basic capabilities doesn't necessarily have to take the experiential form of pain or suffering. ${ }^{16}$

\section{Moral Emotions as Capabilities}

Capabilities, then, are understood as those things one is able to do and to be. With this in mind, there are two ways we can characterise moral emotions in terms of capabilities, depending on whether we focus on what one is able to do because of them or what one is able to be thanks to them. If we decide to conceptualise moral emotions as primarily motivations to engage in moral behaviour, then they are not capabilities in themselves, but rather cognitive-affective mechanisms that ground capabilities. Thus, Sustitia ${ }_{2}$ might be said to have the capability to care for others because she possesses sympathy. But we can also understand moral emotions as capabilities themselves, if we were to conceptualise them as primarily character traits, that is, as dispositions to feel and behave in certain ways. Sympathy, for instance, can be understood as the capability to be sympathetic, that is, as a character trait that disposes one to feel distressed in the presence of others in distress and consequently engage in affiliative behaviour. Moral emotions can thus be understood as either grounding certain capabilities, or as capabilities themselves. For ease of exposition, and given that nothing turns on this largely terminological choice, we shall opt for the second conceptualisation.

Not only can moral emotions be characterised as capabilities, a subset of themthose that ground positive forms of care, such as Sustitia,'s sympathy-can be further characterised as basic capabilities. They can be conceptualised as basic capabilities because they fulfil Nussbaum's two conditions to count as such, namely, being 'central' and being 'good.' To see this, let's go back to our example. Because we are assuming that Sustitia,'s sympathy is grounded in the operations of a reliable mechanism-one that, we are supposing, is innate to her species-, we can determine that the flourishing of this capability is essential to Sustitia ${ }_{2}$ 's functioning as the type of thing she is. At the same time, insofar as her sympathy yields an emotional and behavioural response that can be classified as the morally right one to have given the circumstances, it qualifies as a 'positive' or 'good' moral motivation. While we cannot praise Sustitia ${ }_{2}$ for her behaviour, given that she lacks moral responsibility, we should take into consideration that, whenever she comforts others in distress, she is doing so on the basis of a motivation that implies experiencing as bad something that $i$ bad (namely, the conspecific's distress), and so she is feeling how she should feel, given the circumstances. Additionally, this motivation compels her to behave in a way that is morally appropriate with respect to the situation, and generates good consequences, insofar as the conspecific's distress will be alleviated as a result. For all this, we can say that, whenever Sustitia ${ }_{2}$ behaves sympathetically,

\footnotetext{
${ }^{16}$ Note that this is a conceptual, not empirical, claim. In the 'real world,' the thwarting of a being's basic capabilities may always lead to pain or suffering, but there is no necessary connection between the two, as we shall discuss in the section Theoretical Implications: Moving Beyond Welfarism.
} 
"the world is - temporarily, perhaps even momentarily - a better place," and so, that it is "a good thing that the world contains a subject like this, an individual who acts in this way" (Rowlands 2012, 254).

Not only is sympathy instrumentally valuable because of the good it brings to the world, it can also be plausibly considered as intrinsically valuable, so long as we adopt a pluralistic theory of well-being and consider one's attachments to others, one's relationships of love and care, as part of what it means to lead a good life. This is, in fact, the view adopted by Nussbaum herself (see, e.g., Nussbaum 2007, 345). Accordingly, those moral emotions that ground positive forms of care for others-not just sympathy, but also compassion, patience, tolerance, gratitude, etc.are tacitly present in Nussbaum's list of the basic capabilities of animals. Indeed, Nussbaum considers that the abilities to feel certain emotions and engage in affiliation are amongst the basic capabilities of some animals, and, correspondingly, that these animals "are entitled to lives in which it is open to them to have attachments to others, to love and care for others," as well as "to engage in characteristic forms of bonding and interrelationship" (Ibid., 397-398). It thus seems plausible to consider Sustitia ${ }_{2}$ 's sympathy as a basic capability of hers.

If moral emotions akin to sympathy are indeed basic capabilities, this means that the individuals who possess them are entitled to lead lives in which the exercise of these capabilities remains possible for them. We are now at a point where we can start to see the full dimension of the ethical problems implicit in the example of Sustitia $_{2}$. As we saw, whenever an animal is treated in a way that thwarts one (or several) of her basic capabilities, she is being harmed. There are two ways in which this thwarting can occur: (1) an animal can be precluded from the possibility of exercising her capability, or (2) she can have her capability taken away from her. Sustitia $_{2}$ 's case would be an example of (1). Sustitia 2 still possesses sympathy, but she lacks the possibility of exercising it because of the existence of a physical barrier. Despite not being able to do it, she is still capable of caring for others. She still has her capability, but cannot exercise it. An example of (2) might occur if Sustitia 2 became habituated to the frequent presence of distress cues in her surroundings, to the point where she no longer felt concerned about her conspecifics. She would have become incapable of caring for others. She would have lost her capability. In both cases, Sustitia ${ }_{2}$ is being harmed by whoever has placed her in this situation, because her capability has been thwarted as a result. In the following section, we offer the reasons why the moral problems involved in the thwarting of her moral capability cannot be accounted for in terms of welfare alone.

\section{Theoretical Implications: Moving Beyond Welfarism}

In this section, we offer four considerations that support the claim that the harm affecting Sustitia ${ }_{2}$ cannot be fully captured in terms of experiential welfare. Because we have not given a defence of the capabilities approach, what we will put forward cannot be considered a conclusive argument. However, its strength doesn't solely depend on the strength of the capabilities approach, since, as we mentioned before, other theories could also be successfully employed here. The considerations we will 
offer are reasons that support the need to move beyond welfarism when analysing cases like Sustitia 2 's. While they ultimately rely on intuitions, we hope to show that these reasons are powerful enough to cast serious doubts on the ability of welfarism to rise up to the challenge.

\section{Sustitia $_{2}$ is Being Doubly Harmed}

The first consideration that we can offer is that it doesn't seem enough to simply say that Sustitia ${ }_{2}$ is suffering. In the case of Sustitia ${ }_{1}$, it did seem enough because we didn't describe her as having any particular ability, over and above the ability to experience enjoyment and suffering (and to eat, sleep, and reproduce). What was wrong about the use of the farrowing crate in the case of Sustitia ${ }_{1}$ was not that it prevented her from building a nest for her piglets, or from comforting them if they felt distressed, because we didn't give her these abilities in the first place. All we did was give her the ability to find it painful and stressful, which is why it's enough to say that the farrowing crate harms her because it makes her suffer. In the case of Sustitia ${ }_{2}$, this treatment is also doing something else, namely, preventing her from exercising her moral capability. So simply saying that it makes her suffer isn't enough.

Sustitia $_{2}$, like Sustitia ${ }_{1}$, is harmed because her welfare is being impaired, but she is also harmed because her moral capability is being thwarted. The harm involved in the thwarting of her moral capability adds to the harm involved in her loss of welfare. Sustitia ${ }_{2}$ is, so to speak, doubly harmed. This doesn't mean that the harm that affects Sustitia $_{2}$ is on a different hierarchical order than if it were entirely specifiable in terms of experiential welfare. Our claim is, rather, that if we were to only speak in terms of welfare, we would not capture this additional harm, and so we would only have a partial account of how Sustitia ${ }_{2}$ is being wronged. But Sustitia ${ }_{2}$ 's case is not necessarily worse than Sustitia ${ }_{1}$ 's case. It is simply different. ${ }^{17}$

\section{Distress as a Constituent Part of Caring}

A purely welfarist analysis would distract us from the fact that, under normal circumstances-i.e., if Sustitia ${ }_{2}$ were allowed to comfort the piglet-her suffering wouldn't necessarily be a bad thing. If we accept the claim that caring for others is intrinsically valuable, then the distress that is involved in her sympathy is intrinsically valuable too, insofar as it's part of what it means, for Sustitia 2 , to care for others. Were we to adopt a purely welfare-oriented approach to analyse this case, we could never say that suffering has intrinsic value, and so the ethical nuances of Sustitia 2 's case would not be adequately depicted.

\footnotetext{
17 One could object that this first consideration is question-begging. Of course, in a sense, it is, but that does not necessarily render it useless. By putting forward our intuition that Sustitia 2 is harmed in two different ways, we are making explicit a claim that a welfarist would have to renounce. Those readers who share our intuition may find this a compelling reason to set welfarism aside.
} 
The capabilities approach, in contrast, allows for certain forms of suffering to be valuable in themselves, an idea that Nussbaum expresses by saying that "some animal pains may even be valuable: the grief of an animal for a dead child or parent [...] may be a constituent part of an attachment that is intrinsically good" (Nussbaum 2007, 345; emphasis by authors). One might object to Nussbaum's claim by arguing that an attachment can exist without grief, so grief is a manifestation of an attachment, not a constituent part of it. However, while it's true that an attachment can occur without grief, it's also true that if there is an attachment and certain conditions are met, the attachment yields grief. If it does not, then arguably there is no real attachment. Under certain conditions, grief is the right thing to feel. It's a sign of the quality of an attachment. Whether or not this means that grief is a constituent part of the attachment seems largely a matter of stipulation, but it does seem right to say that if you value the attachment, then you have to value the grief that comes with it.

In the case of Sustitia ${ }_{2}$, it's even clearer, since we haven't given her any other social ability besides her sympathy. This is what caring consists of for Sustitia 2 . We cannot separate it from her distress. They are inextricably intertwined. ${ }^{18}$ If we want to say that her caring is intrinsically good, then we have to value the experiential form that it takes. But, of course, the fact that comforting another can constitute something valuable for a social animal has to be put into perspective, and the circumstances that give rise to this behaviour must be taken into account for a proper ethical assessment to be reached. ${ }^{19}$

\section{Harm Can Take the Form of a Habituation}

One of the advantages of objective theories like the capabilities approach is that they are permeable to the fact that what one is happy or content with is largely shaped by the environment one develops in. Thus, the fact that one is happy most of the time does not necessarily mean that one's life is going well, since one's happiness can be

\footnotetext{
18 This is not an unrealistic trait of Sustitia,'s. Rats given anxiolytics have been found less likely to help a conspecific in need (Ben-Ami Bartal et al. 2016), so distress may be a crucial component of some of the moral motivations of animals.

19 We deliberately point to this because a possible counter-argument might be to say that this implies that the ethical problem of piglet castration could be solved if the sows were allowed to comfort them afterwards. Of course, we believe that such a counter-argument is flawed. There are several further considerations that need to be taken into account. For one, the piglets' suffering would remain and would be an ethical problem even if the sows were allowed to comfort them. In addition, witnessing the suffering of piglets is probably not an isolated event for most sows but something they have to face rather often. A sow currently gives birth to 10-16 piglets per litter, producing 25-30 pigs per year (Kim et al. 2013). All male piglets are normally castrated without pain relief. Additionally, most piglets undergo other painful routine procedures like teeth-clipping or tail-docking, abrupt weaning, re-grouping and transport. All of these procedures are stressful, the witnessing animals cannot escape them, and "the chance of being affected by the distress of their group members is therefore relatively high" (Reimert et al. 2015, 519). The welfare problem might be so big as to outweigh any considerations regarding the intrinsic value of caring for others. But even if we were to consider the sows' caring behaviour as intrinsically valuable in any case, a proper ethical assessment of the situation would take into account the circumstances that originate this behaviour, which are ethically dubious in many respects.
} 
the result of a process of indoctrination or manipulation, or simply a coping mechanism. This was eloquently put by Sen:

A person who has had a life of misfortune, with very little opportunities, and rather little hope, may be more easily reconciled to deprivations than others reared in more fortunate and affluent circumstances. The metric of happiness may, therefore, distort the extent of deprivation, in a specific and biased way. (Sen 1987, 45)

Likewise, in the case of animals, these coping mechanisms may develop and disguise the extent to which animals are harmed in a specific situation, which is one of the reasons why their suffering can be an unreliable measure of their well-being. If Sustitia ${ }_{2}$ eventually became habituated to the suffering of her conspecifics and no longer felt distressed when she perceived it, a welfarist would have to conclude that she is no longer being harmed. In fact, from a welfarist perspective, we would have to say that Sustitia 2 has been benefitted due to this habituation process, insofar as it has led her to stop suffering.

Anyone who considers sympathy and caringness to be intrinsically valuable character traits must conclude that the welfarist analysis of this example is misguided. The habituation process is not beneficial, even if it results in lesser suffering. The habituation process is a further harm that is inflicted upon Sustitia ${ }_{2}$, because an individual who would naturally be sympathetic and caring has become callous by way of the agency of another (i.e., her human caretakers). This harm cannot be accounted for in terms of welfare. In contrast, the capabilities approach allows us to speak of harm, not only when a capability is prevented from being exercised, but also when it is taken away in its entirety. When Sustitia ${ }_{2}$ becomes habituated to her conspecifics' distress, her moral capability is also being thwarted, although in a different way. We can thus continue to speak of harm, even though she is no longer suffering.

\section{Harm is Independent of Suffering}

Welfarists were forced into a moral dilemma when a strain of blind chickens that displayed less signs of distress under crowded conditions was accidentally produced. This sparked an on-going debate on whether we should deliberately disenhance farm animals by use of biotechnology in order to make them incapable of suffering. ${ }^{20}$ The dilemma emerges because the intuitive repugnance that the biotechnological disenhancement of farm animals produces in us cannot be easily reconciled with a welfarist position. If harm depends solely on suffering, then producing animals that cannot suffer should appear as innocuous, even desirable. And yet, this seems highly counter-intuitive.

Reflecting upon the moral capabilities of animals can shed light on at least part of the reason why the biotechnological disenhancement of farm animals would be wrong. This is because the harm that comes from the thwarting of an individual's

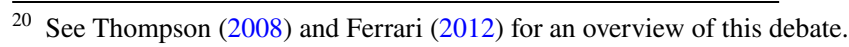


moral capabilities occurs regardless of whether she ever actually suffers as a result

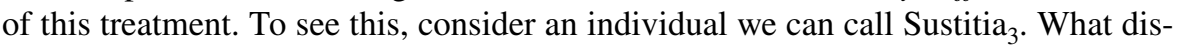
tinguishes her from Sustitia ${ }_{2}$ is that, when Sustitia $_{3}$ was an embryo, she was subjected to a process of genetic engineering aimed at depriving her of the capacity to feel distress. As a consequence of this process of disenhancement, Sustitia ${ }_{3}$ cannot feel distress, and consequently, she cannot feel sympathy either, for the latter is dependent on the former. From a purely welfarist perspective, Sustitia ${ }_{3}$ would not have been harmed by this disenhancement process, since she is, ex hypothesi, incapable of suffering. The capabilities approach, however, allows us to specify at least part of the harm inflicted upon Sustitia $_{3}$, by saying that this disenhancement has deprived her of the capability to care for others. Sustitia ${ }_{3}$ has been forced into a life that contains one less type of good: a life in which she will never get to form attachments and care for others. Her life is poorer as a result, and so it is a worse life.

\section{Practical Implications: How Humans Interfere with the Moral Capabilities of Animals}

In this section, as a last step in our argument, we will evaluate some of the human practices involving animals in light of the considerations we have made. Due to space constraints, we can just give a rough idea of the relevance of our theoretical claims for the field of applied animal ethics and human-animal interactions. Moreover, we are only going to consider those animals that are under direct human care, even though Nussbaum hints at the possibility that the capabilities approach may give rise to certain duties towards wild animals (see Nussbaum 2007, 374ff.). Throughout this section, we will often refer to certain practices that we consider ethically questionable as a whole (like the raising of animals for food), but we will assess them only with respect to the noxious effect they may have upon the moral subjecthood of the animals involved. There are many further ethical concerns with respect to these practices that are well known and have been widely discussed in the literature, but we will proceed by bracketing them and focusing on the issue at hand. This is not meant as a way of lessening the importance of these ethical concerns. Rather, our ultimate aim is to contribute a new aspect to the ethical debate surrounding these practices and perhaps strengthen the case against certain ones.

Until now, we have refrained from referring to real animals and instead used hypothetical constructs to illustrate our point. In what follows, we will refer to actual animal species whose moral capabilities have only recently begun to be studied (if at all). While we still lack the sort of evidence to confidently attribute moral capacities to them, we will proceed by assuming that they are moral subjects, in order to identify potential harms that we may be inadvertently inflicting on them. As we saw, an animal can have her moral capabilities thwarted (1) if she is precluded from the possibility of exercising them, or (2) if her moral capabilities are taken away from her. We shall now consider how these two forms of thwarting may occur in everyday human-animal interactions. For ease of exposition, we are going to divide the (1)type cases into two groups, and consider those that are analogous to Sustitia 2 'sbecause they involve animals witnessing the distress of their conspecifics and 
being physically prevented from intervening-separately from other (1)-type cases in which animals are deprived of further necessary pre-conditions for their moral capabilities to be exercised. We will thus refer to practices that involve humans (a) preventing animals from intervening in response to a conspecific in distress (section "Practices That Involve Animals Witnessing the Distress of Conspecifics"), (b) depriving animals from further pre-conditions for their moral capabilities to be exercised (section "Practices That Deprive Animals of Other Pre-Conditions for the Exercise of Their Moral Capabilities"), and (c) eliminating the animals' ability to act morally (section "Practices That Eliminate the Moral Capabilities of Animals").

\section{Practices That Involve Animals Witnessing the Distress of Conspecifics}

Even though Sustitia 2 was an imaginary example, her life conditions may not differ much from those of real animals who are raised for food. As we have already pointed out, painful and distressing procedures in farm animal husbandry are abundant, and indeed, ethical concerns with respect to the methods involved in breeding, raising, handling, transporting, and slaughtering farm animals have been raised for decades (e.g. Rollin 2003). Due to the overcrowding that characterises intensive farming, these painful procedures will often take place while in the presence of conspecifics. This, however, is an issue that has received comparatively little attention. Only rather recently has it begun to be systematically addressed as a research topic. For instance, it is currently debated whether pigs and other animals brought to slaughter suffer from witnessing their conspecifics' pain and fear (Anil et al. 1996, 1997; Düpjan et al. 2011; Edgar et al. 2012; Reimert et al. 2013). As usual, the focus of these studies has been the welfare problems involved in these situations. The possibility remains, however, that these animals may be moral subjects, and that, upon witnessing their conspecifics' distress, they experience an urge to engage in caring behaviour that they cannot fulfil due to the presence of physical barriers. As we have already explained, this might add a new dimension to the ways in which these animals are being harmed.

Farm animals are not the only class of animals under human care that are often exposed to the distress of conspecifics. Lab animals, too, will frequently find themselves in similar situations. The procedures involved in experimental set-ups include handling the subjects, collecting blood samples, performing orogastric gavage (a technique used to administer nutrients directly to the stomach via an oral tube) (Balcombe et al. 2004), restraining their movements, performing tail-vein injections, and euthanising them (Sharp et al. 2003; Boivin et al. 2016), all of which frequently cause pain or distress to the subjects. Other animals in the laboratory may have perceptual access to these processes and will most likely be prevented from interfering. We already have a significant amount of evidence suggesting that rodents undergo emotional contagion when in the presence of a conspecific in distress (Knapska et al. 2006; Langford et al. 2006; Jeon et al. 2010; Atsak et al. 2011; Burkett et al. 2016), and that, when given the choice, they will help or engage in affiliative behaviour directed at a distressed individual (Church 1959; Rice and Gainer 1962; Evans and Braud 1969; Greene 1969; Langford et al. 2010; Bartal et al. 2011, 2014; Burkett 
et al. 2016). Therefore, in this context it is also important to consider whether the animals are having their moral capabilities thwarted.

\section{Practices That Deprive Animals of Other Pre-Conditions for the Exercise of Their Moral Capabilities}

The exercise of an animal's moral capabilities will most likely depend on the existence of a stable social environment where relationships with conspecifics can take place, develop, and be maintained. The existence of such a stable social environment can thus be plausibly considered as an important pre-condition for the flourishing of an animal's moral capabilities. Many husbandry systems resort to the re-grouping, separation, or even isolation of animals, thus depriving them of this pre-condition, and potentially thwarting their moral capabilities.

This sort of unstable social environment is very common in farms. Farm animals are grouped and re-grouped according to productivity and reproductive state. This could constitute a problem, for instance, for dairy cows, who are gregarious animals and develop complex social relationships, characterised by feeding and resting together, or by engaging in allogrooming. Gutmann et al. (2015) showed that long-term familiarity had a stronger effect on the intensity of social relationships, measured in terms of time and energy investment, than having a very recent shared experience. They conclude that it is actually long-term familiarity that creates preferred social partners in dairy cows. But if farm animals are frequently re-grouped, the only social relationships possible, then, might be short-term relationships. They lose their preferred social partners, and this may hinder the flourishing of their moral capabilities, for evidence suggests that animals have a higher probability of engaging in caring and helping behaviour when they are familiar with the other subject (Cronin 2012; Bartal et al. 2014).

Routine re-grouping is not the only procedure that causes an inadequate social environment for the flourishing of farm animals' moral capabilities. Several of the housing conditions found in factory farms, such as sow stalls and farrowing crates, have been severely criticised, amongst other things, because they result in an enforced isolation from conspecifics (see e.g. Rollin 2011, especially chapter 15). The thwarting of the moral capabilities of these isolated animals adds a new dimension to the welfare problems that such housing methods cause.

Other animals under human care are also deprived of the stable social environment that would be a pre-condition for exercising their moral capabilities. Zoo animals are often separated from each other due to space constraints (if families become too big), and rehoused to other zoos because of breeding programs. Lab animals might be kept in sterile, single housing due to the requirements of a controlled experimental setting. And even if some legislation tries to put a stop to it, companion animals are often kept in isolation from conspecifics, even highly social animals, like parrots, which has been shown to have harming effects (Aydinonat et al. 2014). Furthermore, companion animals kept in shelters, such as dogs, might very often experience the breaking up of social relationships when individuals of their group are rehomed. In this light, the common practice of rescuing dogs from the streets 
may not be as innocuous as is usually considered, as these animals lose their familiar environment and very likely all their well-known partners. They might be brought to a foster home with no other companion dog around them-a situation that could possibly mean fewer opportunities for their moral capabilities to be exercised.

In sum, if the animals in these different examples are subjects with complex social lives that include moral lives, then re-grouping, separating, and isolating them may disrupt or preclude the appearance of those bonds that are a pre-condition for the exercise of their moral capabilities.

\section{Practices That Eliminate the Moral Capabilities of Animals}

In the practices that we have considered until now, the animals involved are, to a bigger or lesser extent, prevented from exercising their moral capabilities. In this final section, we will consider human practices that go over and beyond this, by altogether eliminating the animals' capability to behave morally.

Some human-animal interactions involve breeding, training, conditioning, or modifying the animals with the aim of eliminating some (or all) of their moral capabilities. The most obvious example here is that of fighting animals. Indeed, the training (and also breeding ${ }^{21}$ ) that fighting dogs undergo aims precisely at enhancing their aggressiveness and eliminating any potential caring response to a conspecific in distress (Kalof and Iliopoulou 2011). Cattle used for bullfighting are also selectively bred to enhance aggressiveness (Silva et al. 2006; Correia et al. 2015), as are the chickens used for cock fighting (Guo et al. 2016).

But it is probably in the lab where the elimination of animals' moral capabilities has been performed in the most intentional and methodical manner. Indeed, several psychologists have undertaken this as a research project. Perhaps the most paradigmatic example is Harry Harlow and his experiments on maternal separation, dependency needs, and social deprivation (for an overview on Harlow's research see Harlow 1958; Harlow et al. 1965; Blum 2004). Harlow raised rhesus monkeys from birth onward in bare wire cages, facing partial or total maternal deprivation. He would offer them the choice between two inanimate surrogate mothers: one made of cloth and the other of wire. The infants were found to insistently seek the cloth mothers, even when they were designed to shake them, stab them with blunt spikes, or push them away via a mechanical flap. These monkeys "never experienced mother love, nor any other kind of monkey affection," and when they themselves were impregnated and had their own offspring, they "either completely ignored or abused" their babies, or in many cases killed them (Harlow and Suomi 1971, 1535). By subjecting monkeys to this treatment, as well as to total isolation chambers,

\footnotetext{
21 The case of breeding is peculiar, insofar as selectively breeding for a certain characteristic cannot, in virtue of the non-identity problem, be considered an instance of changing an individual's capabilities. Instead, we would have to say that selective breeding changes the capabilities of the species or the population. We believe that this is nevertheless an instance of harm, because of the intentional manner in which this breeding is performed and the goal behind it. We are assuming that the capabilities approach can accommodate harm inflicted on the capabilities of populations, as well as individuals, but this is a matter that merits further discussion.
} 
Harlow systematically created individuals who were completely "deficient in social play and sexual behavior," as well as "hyperaggressive in peer interaction" (Arling and Harlow 1967, 371).

Harlow's experiments, as shocking as they sound, should not be considered an isolated event in psychology. During the past 30 years, on-going maternal deprivation experiments, conducted for example at the NIH in the US, have subjected hundreds of infant macaques to similar conditions as Harlow's experiments. They are heavily criticised from a bioethical perspective for being both unnecessary and cruel (Novak 2014; Medical Research Modernization Committee 2017). The potential elimination of the monkeys' moral capabilities is another factor to consider in the ethical assessment of these tests.

Further examples of experiments performed with the aim of interfering in the animals' moral capabilities include Tulogdi et al. (2014), who subjected rats to postweaning social isolation, thereby inducing deficits in pro-social behaviour. These deficits were eliminated by resocialisation during adulthood, but the rats' abnormal aggressiveness remained resilient to this treatment. Hernandez-Lallement et al. (2016) have also induced deficits in pro-social behaviour in rats by performing surgery aimed at damaging the amygdala (brain area responsible for emotion and affiliation). They plan to continue their research along these lines in order to produce "an animal model of callousness," for which "[r]odents offer a cheap, convenient and ethically less controversial alternative to non-human primates" (Hernandez-Lallement et al. 2018). Our argument helps to shed some light on the ethical problems that are, in fact, involved in such experiments.

As in the hypothetical example of Sustitia ${ }_{3}$, some human practices may destroy the moral capabilities of animals indirectly, as an unintended side effect of a treatment that has other aims. For example, there have been reports of rats becoming habituated to distress cues from conspecifics after repeated exposure to them during pro-sociality experiments (Church 1959). The mother-infant relationship is also artificially terminated in the case of many farm, zoo, and lab animals, as well as for some companion animals, e.g., if puppies are sold before they reach an appropriate age. As the Harlow experiments exemplify, the absence of an appropriate motherinfant bond may have profound effects on the development of the moral capabilities of animals. And lastly, the social isolation that can be found in many farms, zoos, labs, and even some households, may not just prevent the animals from exercising their moral capabilities, but also, in the long run, effectively eliminate their capacity to care for others. The humans who are causally responsible should, arguably, be blamed for this harm, even if it was unintended. This would especially be the case if the humans were aware of this side effect, and simply assumed it as an inevitable consequence.

\section{Conclusion}

When we initially set out to investigate the ethical implications of considering that some animals are moral subjects, we expected it to be a conceptual exploration, with little relevance outside the proverbial armchair. Rather the opposite turned out to 
be the case. We have found many contexts, including routine procedures in farms, labs, and in our homes, where humans potentially interfere with, hinder, or destroy the moral capabilities of animals. And by opening up to other normative theories besides the capabilities approach we could perhaps find further examples. We leave that to future research, and hope to at least have given a good sense of how the possibility of moral subjecthood in animals creates conceptual space for a type of harm that has been little, if at all, discussed, and that may be very real and important. Whether or not welfarists can find a way of capturing this harm remains to be seen, but we hope to have convincingly shown how, in its purely hedonistic formulation, it is unlikely that welfarism can account for this harm.

Acknowledgements Open access funding provided by Austrian Science Fund (FWF). An early version of this paper was presented at the conference 'Ethical Theories and the Animal Issue: between Science and Philosophy' held at the University of Milan in 2016. The authors would like to thank the attendants, and especially Mark Rowlands, for their helpful feedback. This paper also hugely benefitted from comments by Samuel Camenzind, Herwig Grimm, Stefan Schwarzburg, and various anonymous reviewers.

Funding This research was partially funded by the Messerli Foundation (Project Number FA37314006) and the Austrian Science Fund (Project Number P 31466-G32).

Open Access This article is distributed under the terms of the Creative Commons Attribution 4.0 International License (http://creativecommons.org/licenses/by/4.0/), which permits unrestricted use, distribution, and reproduction in any medium, provided you give appropriate credit to the original author(s) and the source, provide a link to the Creative Commons license, and indicate if changes were made.

\section{References}

Andrews, Kristin, and Lori Gruen. 2014. Empathy in Other Apes. In Empathy and Morality, ed. Heidi Maibon, 193-209. New York: Oxford University Press.

Andrews, Kristin, and Susana Monsó. In preparation. "Animal Moral Psychologies." To appear in The Oxford Handbook of Moral Psychology, ed. John Doris and Manuel Vargas. New York: Oxford University Press.

Anil, M.Haluk, Justin L. McKinstry, M. Field, and Richard G. Rodway. 1997. Lack of Evidence for Stress Being Caused to Pigs by Witnessing the Slaughter of Conspecifics. Animal Welfare 6(1): 3-8.

Anil, M.Haluk, John Preston, Justin L. McKinstry, Richard G. Rodwayl, and Steven N. Brown. 1996. An Assessment of Stress Caused in Sheep by Watching Slaughter of Other Sheep. Animal Welfare 5(4): 435-441.

Arling, Gary L., and Harry F. Harlow. 1967. Effects of Social Deprivation on Maternal Behavior of Rhesus Monkeys. Journal of Comparative and Physiological Psychology 64(3): 371-377.

Atsak, Piray, Marie Orre, Petra Bakker, Leonardo Cerliani, Benno Roozendaal, Valeria Gazzola, Marta Moita, and Christian Keysers. 2011. Experience Modulates Vicarious Freezing in Rats: A Model for Empathy. PLOS ONE 6(7): e21855.

Aydinonat, Denise, Dustin J. Penn, Steve Smith, Yoshan Moodley, Franz Hoelzl, Felix Knauer, and Franz Schwarzenberger. 2014. Social Isolation Shortens Telomeres in African Grey Parrots (Psittacus Erithacus Erithacus). PLoS ONE 9(4): e93839.

Balcombe, Jonathan P., Neal D. Barnard, and Chad Sandusky. 2004. Laboratory Routines Cause Animal Stress. Journal of the American Association for Laboratory Animal Science 43(6): 42-51.

Bartal, Ben-Ami, Jean Decety Inbal, and Peggy Mason. 2011. Empathy and Pro-Social Behavior in Rats. Science 334 (6061): 1427-1430.

Bartal, Ben-Ami, Haozhe Shan Inbal, Nora M.R. Molasky, Teresa M. Murray, Jasper Z. Williams, Jean Decety, and Peggy Mason. 2016. Anxiolytic Treatment Impairs Helping Behavior in Rats. Frontiers in Psychology. https://doi.org/10.3389/fpsyg.2016.00850. 
Bekoff, Marc, and Jessica Pierce. 2009. Wild Justice: The Moral Lives of Animals. Chicago: University Of Chicago Press.

Ben-Ami Bartal, Inbal, David A. Rodgers, Maria Sol Bernardez Sarria, Jean Decety, and Peggy Mason. 2014. Pro-Social Behavior in Rats is Modulated by Social Experience. eLife. https://doi. org/10.7554/eLife.01385.001.

Benz-Schwarzburg, Judith. 2012. Verwandte Im Geiste-Fremde im Recht: Sozio-Kognitive Fähigkeiten bei Tieren und ihre Relevanz für Tierethik und Tierschutz. Tierrechte - Menschenpflichten, vol. 16. Erlangen: Harald Fischer Verlag.

Benz-Schwarzburg, Judith, and Andrew Knight. 2011. Cognitive Relatives yet Moral Strangers? Journal of Animal Ethics 1(1): 9-36.

Blum, Deborah. 2004. Love At Goon Park: Harry Harlow and the Science of Affection. New York: Berkley Books.

Boivin, Gregory P., Michael A. Bottomley, and Nadja Grobe. 2016. Responses of Male C57BL/6 N Mice to Observing the Euthanasia of Other Mice. Journal of the American Association for Laboratory Animal Science: JAALAS 55(4): 406-411.

Broom, Donald M. 1991. Animal Welfare: Concepts and Measurement. Journal of Animal Science 69(10): 4167-4175.

Brosnan, Sarah F., and Frans B.M. de Waal. 2003. Monkeys Reject Unequal Pay. Nature 425 (6955): 297-299.

Brosnan, Sarah F., Hillary C. Schiff, and Frans B.M. de Waal. 2005. Tolerance for Inequity May Increase with Social Closeness in Chimpanzees. Proceedings of the Royal Society B: Biological Sciences 272(1560): 253-258.

Brosnan, Sarah F., Catherine Talbot, Megan Ahlgren, Susan P. Lambeth, and Steven J. Schapiro. 2010. Mechanisms Underlying Responses to Inequitable Outcomes in Chimpanzees, Pan Troglodytes. Animal Behaviour 79(6): 1229-1237.

Burkart, Judith M., Ernst Fehr, Charles Efferson, and Carel P. van Schaik. 2007. Other-Regarding Preferences in a Non-Human Primate: Common Marmosets Provision Food Altruistically. Proceedings of the National Academy of Sciences 104(50): 19762-19766.

Burkett, James P., Elissar Andari, Zachary V. Johnson, Daniel C. Curry, Frans B.M. de Waal, and Larry J. Young. 2016. Oxytocin-Dependent Consolation Behavior in Rodents. Science 351(6271): $375-378$.

Carron, Paul. 2018. Ape Imagination? A Sentimentalist Critique of Frans de Waal's Gradualist Theory of Human Morality. Biology and Philosophy 33(3-4): 22.

Church, Russell M. 1959. Emotional Reactions of Rats to the Pain of Others. Journal of Comparative and Physiological Psychology 52(2): 132-134.

Clay, Zanna, and Frans B.M. de Waal. 2013. Bonobos Respond to Distress in Others: Consolation across the Age Spectrum. PLoS ONE 8(1): e55206.

Cools, Annemieke K.A., Alain J.-M. Van Hout, and Mark H.J. Nelissen. 2008. Canine Reconciliation and Third-Party-Initiated Postconflict Affiliation: Do Peacemaking Social Mechanisms in Dogs Rival Those of Higher Primates? Ethology 114(1): 53-63.

Cordoni, Giada, Elisabetta Palagi, and Silvana Borgognini Tarli. 2006. Reconciliation and Consolation in Captive Western Gorillas. International Journal of Primatology 27(5): 1365-1382.

Correia, Pedro, Erica Baron, and Fernando Moreira da Silva. 2015. Selection Traits of Lidia Cattle for Azorean Street Bullfighting. Archivos de Zootecnia 64(245): 27-34.

Cozzi, Alessandro, Claudio Sighieri, Angelo Gazzano, Christine J. Nicol, and Paolo Baragli. 2010. PostConflict Friendly Reunion in a Permanent Group of Horses (Equus Caballus). Behavioural Processes 85(2): 185-190.

Crary, Alice. 2010. Minding What Already Matters: A Critique of Moral Individualism. Philosophical Topics 38(1): 17-49.

Cronin, Katherine A. 2012. Prosocial Behaviour in Animals: The Influence of Social Relationships, Communication and Rewards. Animal Behaviour 84(5): 1085-1093.

Cronin, Katherine A., Kori K.E. Schroeder, and Charles T. Snowdon. 2010. Prosocial Behaviour Emerges Independent of Reciprocity in Cottontop Tamarins. Proceedings Biological Sciences/The Royal Society 277(1701): 3845-3851.

Cronin, Katherine A., and Charles T. Snowdon. 2008. The Effects of Unequal Reward Distributions on Cooperative Problem Solving by Cottontop Tamarins, Saguinus Oedipus. Animal Behaviour 75(1): $245-257$. 
Custance, Deborah, and Jennifer Mayer. 2012. Empathic-like Responding by Domestic Dogs (Canis Familiaris) to Distress in Humans: An Exploratory Study. Animal Cognition 15(5): 851-859.

Dawkins, Marian S. 2006. Through Animal Eyes: What Behaviour Tells Us. Applied Animal Behaviour Science 100(1-2): 4-10.

DeGrazia, David. 1996. Taking Animals Seriously: Mental Life and Moral Status. Cambridge: Cambridge University Press.

DeGrazia, David. 2005. Regarding the Last Frontier of Bigotry. Logos 4(2). http://www.logosjourn al.com/issue_4.2/degrazia.htm. Accessed 2nd Feb 2017.

Duncan, Ian J.H. 1993. Welfare Is to Do with What Animals Feel. Journal of Agricultural and Environmental Ethics 6(2): 8-14.

Duncan, Ian J.H. 2004. A Concept of Welfare Based on Feelings. In The Well-Being of Farm Animals: Challenges and Solutions, ed. G. John Benson and Bernard E. Rollin, 85-102., Issues in Animal Bioethics Oxford: Blackwell.

Düpjan, Sandra, Armin Tuchscherer, Jan Langbein, Peter-Christian Schön, Gerhard Manteuffel, and Birger Puppe. 2011. Behavioural and Cardiac Responses towards Conspecific Distress Calls in Domestic Pigs (Sus Scrofa). Physiology \& Behavior 103(5): 445-452.

Edgar, Joanne L., John C. Lowe, Elizabeth S. Paul, and Christine J. Nicol. 2011. Avian Maternal Response to Chick Distress. Proceedings of the Royal Society of London B: Biological Sciences March: rspb20102701.

Edgar, Joanne L., Christine J. Nicol, C.C.A. Clark, and Elizabeth S. Paul. 2012. Measuring empathic responses in animals. Applied Animal Behaviour Science 138(3-4): 182-193.

Epicurus. Kyriai Doxai (Principal Doctrines). Translation by Peter Saint-Andre (2008). Available at http://monadnock.net/epicurus/principal-doctrines.html. Accessed 27 Sept 2017.

European Food Safety Authority (EFSA). 2007. Animal Health and Welfare Aspects of Different Housing and Husbandry Systems for Adult Breeding Boars, Pregnant, Farrowing Sows and Unweaned Piglets-Scientific Opinion of the Panel on Animal Health and Welfare. EFSA Journal. https://doi.org/10.2903/j.efsa.2007.572.

Evans, Valerie E., and William G. Braud. 1969. Avoidance of a Distressed Conspecific. Psychonomic Science 15(3): 166.

Ferrari, Arianna. 2012. Animal Disenhancement for Animal Welfare: The Apparent Philosophical Conundrums and the Real Exploitation of Animals. A Response to Thompson and Palmer. Nanoethics 6: 65-76.

Fitzpatrick, Simon. 2017. Animal Morality: What Is the Debate About? Biology and Philosophy 32(6): 1151-1183.

Fraser, Orlaith N., and Thomas Bugnyar. 2010. Do Ravens Show Consolation? Responses to Distressed Others. PLoS ONE 5(5): e10605.

Fraser, Orlaith N., Daniel Stahl, and Filippo Aureli. 2008. Stress Reduction through Consolation in Chimpanzees. Proceedings of the National Academy of Sciences 105(25): 8557-8562.

Goumon, Sébastien, and Marek Špinka. 2016. Emotional Contagion of Distress in Young Pigs Is Potentiated by Previous Exposure to the Same Stressor. Animal Cognition 19(3): 501-511.

Greene, James T. 1969. Altruistic Behavior in the Albino Rat. Psychonomic Science 14(1): 47-48.

Guo, Xing, Qi Fang, Chendong Ma, Bangyuan Zhou, Yi Wan, and Runshen Jiang. 2016. WholeGenome Resequencing of Xishuangbanna Fighting Chicken to Identify Signatures of Selection. Genetics Selection Evolution 48: 62.

Gutmann, Anke K., Marek Špinka, and Christoph Winckler. 2015. Long-Term Familiarity Creates Preferred Social Partners in Dairy Cows. Applied Animal Behaviour Science 169: 1-8.

Harlow, Harry F. 1958. The Nature of Love. American Psychologist 13: 673-685.

Harlow, Harry F., Robert O. Dodsworth, and Margaret K. Harlow. 1965. Total Social Isolation in Monkeys. Proceedings of the National Academy of Sciences of the United States of America 54(1): 90-97.

Harlow, H., and Stephen J. Suomi. 1971. Social Recovery by Isolation-Reared Monkeys. Proceedings of the National Academy of Sciences of the United States of America 68(7): 1534-1538.

Hernandez-Lallement, Julen, Marijn van Wingerden, and Tobias Kalenscher. 2018. Towards an Animal Model of Callousness. Neuroscience and Biobehavioral Reviews 91: 121-129.

Hernandez-Lallement, Julen, Marijn van Wingerden, Sandra Schäble, and Tobias Kalenscher. 2016. Basolateral Amygdala Lesions Abolish Mutual Reward Preferences in Rats. Neurobiology of Learning and Memory 127: 1-9. 
Herskin, Mette S., Karin H. Jensen, and Karen Thodberg. 1998. Influence of Environmental Stimuli on Maternal Behaviour Related to Bonding, Reactivity and Crushing of Piglets in Domestic Sows. Applied Animal Behaviour Science 58(3): 241-254.

Horner, Victoria, J. Devyn Carter, Malini Suchak, and Frans B.M. de Waal. 2011. Spontaneous Prosocial Choice by Chimpanzees. Proceedings of the National Academy of Sciences, August.

Huber, Annika, Anjuli L.A. Barber, Tamás Faragó, Corsin A. Müller, and Ludwig Huber. 2017. Investigating Emotional Contagion in Dogs (Canis Familiaris) to Emotional Sounds of Humans and Conspecifics. Animal Cognition 20(4): 703-715.

Ikkatai, Yuko, Shigeru Watanabe, and Ei-Ichi Izawa. 2016. Reconciliation and Third-Party Affiliation in Pair-Bond Budgerigars (Melopsittacus Undulatus). Behaviour 153(9-11): 1173-1193.

Jeon, Daejong, Sangwoo Kim, Mattu Chetana, H. Daewoong Jo, Earl Ruley, Shih-Yao Lin, Dania Rabah, Jean-Pierre Kinet, and Hee-Sup Shin. 2010. Observational Fear Learning Involves Affective Pain System and Cav1.2 Ca2 + Channels in ACC. Nature Neuroscience 13(4): 482-488.

Kalof, Linda, and Maria Andromachi Iliopoulou. 2011. Abusing the Human-Animal Bond: On the Making of Fighting Dogs. In The Psychology of the Human-Animal Bond, ed. Christopher Blazina, Güler Boyraz, and David Shen-Miller, 321-332. New York: Springer.

Kikusui, Takefumi, Shu Takigami, Yukari Takeuchi, and Yuji Mori. 2001. Alarm Pheromone Enhances Stress-Induced Hyperthermia in Rats. Physiology \& Behavior 72(1-2): 45-50.

Kim, Sung Woo, Alexandra C. Weaver, Yan Bin Shen, and Yan Zhao. 2013. Improving Efficiency of Sow Productivity: Nutrition and Health. Journal of Animal Science and Biotechnology 4(1): 26.

Knapska, Ewelina, Evgeni Nikolaev, Pawel Boguszewski, Grazyna Walasek, Janusz Blaszczyk, Leszek Kaczmarek, and Tomasz Werka. 2006. Between-Subject Transfer of Emotional Information Evokes Specific Pattern of Amygdala Activation. Proceedings of the National Academy of Sciences of the United States of America 103(10): 3858-3862.

Korsgaard, Christine M. 2006. Morality and the Distinctiveness of Human Action. In Primates and Philosophers: How Morality Evolved, ed. Stephen Macedo and Josiah Ober, 98-119. Princeton: Princeton University Press.

Kutsukake, Nobuyuki, and Duncan L. Castles. 2004. Reconciliation and Post-Conflict Third-Party Affiliation among Wild Chimpanzees in the Mahale Mountains, Tanzania. Primates; Journal of Primatology 45(3): 157-165.

Lakshminarayanan, Venkat R., and Laurie R. Santos. 2008. Capuchin Monkeys Are Sensitive to Others' Welfare. Current Biology 18(21): R999-R1000.

Langford, Dale J., Sara E. Crager, Zarrar Shehzad, Shad B. Smith, Susana G. Sotocinal, Jeremy S. Levenstadt, Mona Lisa Chanda, Daniel J. Levitin, and Jeffrey S. Mogil. 2006. Social Modulation of Pain as Evidence for Empathy in Mice. Science 312(5782): 1967-1970.

Langford, Dale J., Alexander H. Tuttle, Kara Brown, Sonya Deschenes, David B. Fischer, Amelia Mutso, Kathleen C. Root, Susana G. Sotocinal, Matthew A. Stern, Jeffrey S. Mogil, and Wendy F. Sternberg. 2010. Social Approach to Pain in Laboratory Mice. Social Neuroscience 5(2): 163-170.

Linzey, Andrew, and Dan Cohn-Sherbok. 1997. After Noah: Animals and the Liberation of Theology. London: Mowbray.

Machan, Tibor R. 2002. Why Human Beings May Use Animals. Journal of Value Inquiry 36: 9-14.

Massen, Jorg J.M., Lisette M. Van Den Berg, Berry M. Spruijt, and Elisabeth H.M. Sterck. 2012. Inequity Aversion in Relation to Effort and Relationship Quality in Long-Tailed Macaques (Macaca Fascicularis). American Journal of Primatology 74(2): 145-156.

Masserman, Jules, Stanley Wechkin, and William Terris. 1964. 'Altruistic' Behaviour in Rhesus Monkeys. American Journal of Psychiatry 121(6): 584-585.

McCloskey, H.J. 1987. The Moral Case for Experimentation on Animals. The Monist 70(1): 64-82.

Medical Research Modernization Committee. 2017. A Critique of Maternal Deprivation Experiments on Primates. http://www.mrmcmed.org/mom.html. Accessed 16 Jan 2017.

Monsó, Susana. 2017. Morality Without Mindreading. Mind and Language 32(3): 338-357.

Novak, Bridgett. 2014. Animal Research at NIH Lab Challenged by Members of Congress. Reuters U.S., Dec 24, 2014. http://www.reuters.com/article/us-nih-ethics-baby-monkeys-idUSKBNOK300120 141225. Accessed 16 Jan 2017.

Nozick, Robert. 1974. Anarchy, State, and Utopia. New York: Basic Books.

Nussbaum, Martha C. 2007. Frontiers of Justice: Disability, Nationality, Species Membership. Cambridge: Harvard University Press. 
Nussbaum, Martha C. 2004. Beyond 'Compassion and Humanity': Justice for Nonhuman Animals. In Animal Rights: Current Debates and New Directions, ed. Cass R. Sunstein and Martha C. Nussbaum, 299-320. New York: Oxford University Press.

Oberliessen, Lina, Julen Hernandez-Lallement, Sandra Schäble, Marijn van Wingerden, Maayke Seinstra, and Tobias Kalenscher. 2016. Inequity Aversion in Rats, Rattus Norvegicus. Animal Behaviour 115: $157-166$.

Palagi, Elisabetta, and Giada Cordoni. 2009. Postconflict Third-Party Affiliation in Canis Lupus: Do Wolves Share Similarities with the Great Apes? Animal Behaviour 78(4): 979-986.

Palagi, Elisabetta, Stefania Dall'Olio, Elisa Demuru, and Roscoe Stanyon. 2014. Exploring the Evolutionary Foundations of Empathy: Consolation in Monkeys. Evolution and Human Behavior 35(4): 341-349.

Park, Kyum J., Hawsun Sohn, Yong R. An, Dae Y. Moon, Seok G. Choi, and H.An. Doo. 2012. An Unusual Case of Care-Giving Behavior in Wild Long-Beaked Common Dolphins (Delphinus Capensis) in the East Sea. Marine Mammal Science 29(4): E508-E514.

Parr, Lisa A. 2001. Cognitive and Physiological Markers of Emotional Awareness in Chimpanzees (Pan Troglodytes). Animal Cognition 4(3-4): 223-229.

Penn, Derek C., Keith J. Holyoak, and Daniel J. Povinelli. 2008. Darwin's Mistake: Explaining the Discontinuity between Human and Nonhuman Minds. Behavioral and Brain Sciences 31(2): 109-130.

Plotnik, Joshua M., and Frans B.M. de Waal. 2014. Asian Elephants (Elephas Maximus) Reassure Others in Distress. PeerJ. https://doi.org/10.7717/peerj.278.

Pluhar, Evelyn B. 1995. Beyond Prejudice: The Moral Significance of Human and Nonhuman Animals. Durham: Duke University Press.

Purves, Duncan, and Nicolas Delon. 2018. Meaning in the Lives of Humans and Other Animals. Philosophical Studies 175(2): 317-338.

Range, Friederike, Lisa Horn, Zsófia Viranyi, and Ludwig Huber. 2008. The Absence of Reward Induces Inequity Aversion in Dogs. Proceedings of the National Academy of Sciences December.

Rawls, John. 1971. A Theory of Justice. Cambridge: Harvard University Press.

Reimert, Inonge, J. Elizabeth Bolhuis, Bas Kemp, and T. Bas Rodenburg. 2013. Indicators of Positive and Negative Emotions and Emotional Contagion in Pigs. Physiology \& Behavior 109: 42-50.

Reimert, Inonge, J. Elizabeth Bolhuis, Bas Kemp, and T. Bas Rodenburg. 2015. Emotions on the Loose: Emotional Contagion and the Role of Oxytocin in Pigs. Animal Cognition 18(2): 517-532.

Rice, Christopher M. 2013. Defending the Objective List Theory of Well-Being. Ratio 26(2): 196-211.

Rice, George E., and Priscilla Gainer. 1962. 'Altruism' in the Albino Rat. Journal of Comparative and Physiological Psychology 55: 123-125.

Rollin, Bernard E. 2003. Farm Animal Welfare: Social, Bioethical, and Research Issues. Ames: Wiley-Blackwell.

Rollin, Bernard E. 2011. Putting the Horse before Descartes. My Life's Work on Behalf of Animals. Philadelphia: Temple University Press.

Rollin, Bernard E. 2004. The Ethical Imperative to Control Pain and Suffering in Farm Animals. In The Well-Being of Farm Animals: Challenges and Solutions, ed. G. John Benson and Rollin, Bernard E., 3-20. Issues in Animal Bioethics. Oxford: Blackwell.

Rowlands, Mark. 2002. Animals Like Us. London: Verso.

Rowlands, Mark. 2011. Animals That Act for Moral Reasons. In The Oxford Handbook of Animal Ethics, ed. T. Beauchamp and R.G. Frey, 519-546. New York: Oxford University Press.

Rowlands, Mark. 2012. Can Animals Be Moral?. New York: Oxford University Press.

Rowlands, Mark. 2017. Moral Subjects. In The Routledge Handbook of Philosophy of Animal Minds, ed. K. Andrews and J. Beck, 469-474. Oxon: Routledge.

RSPCA. 2016. Pig Welfare-Tail Docking, Teeth Grinding, Castration, Sow Stalls. https://www.rspca .org.uk:443/adviceandwelfare/farm/pigs/keyissues. Accessed 28 Nov 2016.

Rutgers, Bart, and Robert Heeger. 1999. Inherent Worth and Respect for Animal Integrity. In Recognizing the Intrinsic Value of Animals: Beyond Animal Welfare, ed. Marcel Dol et al. Assen: Van Gorcum.

Ryder, Richard D. 1999. Painism: Some Moral Rules for the Civilized Experimenter. Cambridge Quarterly of Healthcare Ethics 8(1): 35-42.

Sapontzis, S.F. 1987. Morals, Reason, and Animals. Philadelphia: Temple University Press.

Sato, Nobuya, Ling Tan, Kazushi Tate, and Maya Okada. 2015. Rats Demonstrate Helping Behavior toward a Soaked Conspecific. Animal Cognition 18(5): 1039-1047. 
Schmelz, Martin, Sebastian Grueneisen, Alihan Kabalak, Jürgen Jost, and Michael Tomasello. 2017. Chimpanzees Return Favors at a Personal Cost. Proceedings of the National Academy of Sciences 114(28): 7462-7467.

Schmidt, Kirsten. 2011. Concepts of Animal Welfare in Relation to Positions in Animal Ethics. Acta Biotheoretica 59(2): 153-171.

Schwartz, Lindsay P., Alan Silberberg, Anna H. Casey, David N. Kearns, and Burton Slotnick. 2017. Does a Rat Release a Soaked Conspecific Due to Empathy? Animal Cognition 20(2): 299-308.

Seed, Amanda M., Nicola S. Clayton, and Nathan J. Emery. 2007. Postconflict Third-Party Affiliation in Rooks, Corvus Frugilegus. Current Biology: CB 17(2): 152-158.

Sen, Amartya. 1987. On Ethics and Economics. Oxford: Blackwell.

Shapiro, Paul. 2006. Moral Agency in Other Animals. Theoretical Medicine and Bioethics 27(4): 357-373.

Sharp, Jody, Zammit Timothy, Azar Toni, and Lawson David. 2003. Are "By-Stander" Female SpragueDawley Rats Affected By Experimental Procedures? Contemporary Topics in Laboratory Animal Science 42(1): 19-27.

Silva, Beatriz, Ana Gonzalo, and Javier Cañón. 2006. Genetic Parameters of Aggressiveness, Ferocity and Mobility in the Fighting Bull Breed. Animal Research 55(1): 65-70.

Smith, Adam S., and Zuoxin Wang. 2014. Hypothalamic Oxytocin Mediates Social Buffering of the Stress Response. Biological Psychiatry 76(4): 281-288.

Sumner, L.W. 1996. Welfare, Happiness, and Ethics. Oxford: Oxford University Press.

Thompson, Paul B. 2008. The Opposite of Human Enhancement: Nanotechnology and the Blind Chicken Problem. Nanoethics 2: 305-316.

Tulogdi, Áron, Máté Tóth, Beáta Barsvári, László Biró, Éva Mikics, and József Haller. 2014. Effects of Resocialization on Post-Weaning Social Isolation-Induced Abnormal Aggression and Social Deficits in Rats. Developmental Psychobiology 56(1): 49-57.

Waal, De, and B.M. Frans. 2008. Putting the Altruism Back into Altruism: The Evolution of Empathy. Annual Review of Psychology 59: 279-300.

Waal, De, B.M. Frans, and Angeline van Roosmalen. 1979. Reconciliation and Consolation among Chimpanzees. Behavioral Ecology and Sociobiology 5(1): 55-66.

Warneken, Felix, Brian Hare, Alicia P. Melis, Daniel Hanus, and Michael Tomasello. 2007. Spontaneous Altruism by Chimpanzees and Young Children. PLoS Biology 5(7): e184.

Warneken, Felix, and Michael Tomasello. 2006. Altruistic Helping in Human Infants and Young Chimpanzees. Science 311(5765): 1301-1303.

Wascher, Claudia A.F., Isabella B.R. Scheiber, and Kurt Kotrschal. 2008. Heart Rate Modulation in Bystanding Geese Watching Social and Non-Social Events. Proceedings of the Royal Society of London B: Biological Sciences 275(1643): 1653-1659.

Watanabe, Shigeru, and Kunihiko Ono. 1986. An Experimental Analysis of 'empathic' Response: Effects of Pain Reactions of Pigeon upon Other Pigeon's Operant Behavior. Behavioural Processes 13(3): 269-277.

Webster, John. 2005. Animal Welfare: Limping towards Eden. Oxford: Blackwell.

Wechkin, Stanley, Jules Masserman, and William Terris. 1964. Shock to a Conspecific as an Aversive Stimulus. Psychonomic Science 1: 17-18.

White, Thomas. 2007. In Defense of Dolphins: The New Moral Frontier. Oxford: Wiley-Blackwell.

Yong, Min Hooi, and Ted Ruffman. 2014. Emotional Contagion: Dogs and Humans Show a Similar Physiological Response to Human Infant Crying. Behavioural Processes 108: 155-165. 